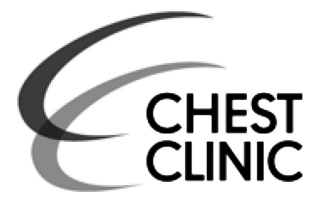

Correspondence to Dr Laurence Drake, Greensands Medical Practice, Brook End, Potton, Bedfordshire

SG19 2QS, UK;

laurence.drake@doctors.org.uk

Received 10 September 2014 Accepted 11 September 2014 Published Online First 26 September 2014

\title{
PULMONARY PUZZLES
}

\section{I hear the heartbeat, or things that go bump-bump in the night...}

\section{Laurence Drake}

A 47-year-old woman telephones your surgery and says, "I can hear my boyfriend's heartbeat-from three feet away!" Do you:

A. arrange an urgent psychiatric review for this obviously delusional woman?

B. arrange an urgent psychiatric review for the Editors of Thorax for publishing a cardiology case report?

C. or do something else?

On urgent review after the phone call, you can hear what sounds like his amplified heart sounds from over a metre away, especially if he leans backwards.

This was a fit 50-year-old man, who had crashed his motorcycle at $70 \mathrm{mph}$ racing at Snetterton circuit the previous day. A left clavicular fracture (figure 1) had been diagnosed in the local A\&E Department, and he was discharged. Later that night he had become aware of a 'strange knocking sound' simultaneous with his heartbeat. On direct questioning, he admitted to mild dyspnoea while walking up the slope to the surgery.

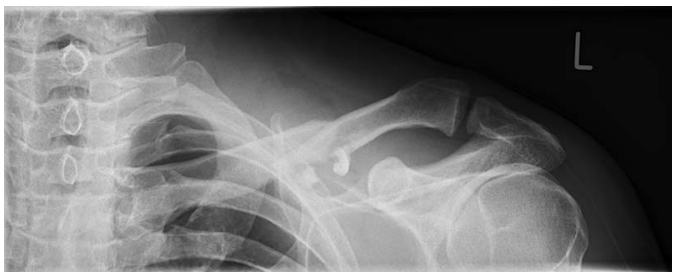

Figure 1 Radiograph showing patient's fractured clavicle.

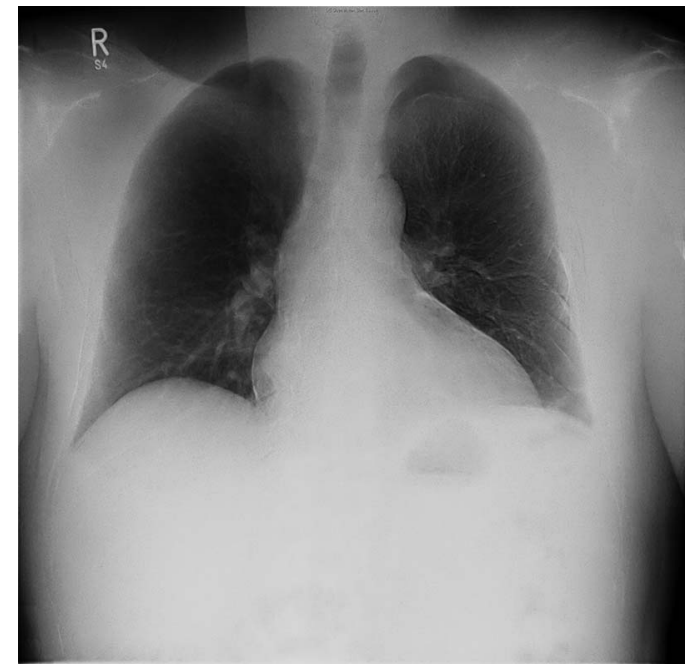

Figure 2 Chest X-ray showing left apical pneumothorax.

On examination he had slightly reduced left apical breath sounds, with no surgical emphysema or any other chest abnormalities. An urgent chest X-ray (figure 2) confirmed a shallow uncomplicated left apical pneumothorax, which subsequently resolved spontaneously.

\section{QUESTION}

What is the diagnosis? 


\section{Chest clinic}

\section{ANSWER}

Final diagnosis: fractured clavicle with apical pneumothorax and positive Hamman's sign

Hamman's sign was first described in $1937^{1}$ as a crunching, bubbling, popping, crackling or clicking sound synchronous with the heartbeat in association with a pneumomediastinum, or left-sided pneumothorax. ${ }^{2-4}$ The noise is thought to be caused by the heart beating against air-filled tissues or pockets, or cyclical channelling of free pleural air through a lung fissure, ${ }^{3}$ with possibly the effect being magnified by the resonating chamber of the pneumothorax cavity. By $2010^{5}$ the sign was felt to be in danger of neglect, but it was felt it "should be kept "alive" as it may provide a clue to the diagnosis of a left-sided pneumothorax or pneumomediastinum in patients presenting with leftsided chest pain, even when radiological examination is not supportive'.

Learning points: Some tall tales are true, and Rice Krispies are not the only differential diagnosis of 'Snap, Crackle, Pop'!
Acknowledgements Joel Melton, Consultant Orthopaedic Consultant, Addenbrooke's Hospital, Hills Road, Cambridge CB2 OQQ, who kindly supplied the attached X-rays. Professor Andrew Bush of Thorax for help with the manuscript.

Competing interests None.

Patient consent Obtained.

Provenance and peer review Not commissioned; internally peer reviewed.

\section{REFERENCES}

1 Hamman L. Spontaneous interstitial emphysema of the lungs. Tr Assoc Am Physicians 1937:52:311-19.

2 Scadding JG, Wood P. Systolic clicks due to left-sided pneumothorax. Lancet 1939;2:1208-11.

3 Baumann MH, Sahn SA. Hamman's sign revisited. Pneumothorax or pneumomediastinum? Chest 1992;102:1281-82.

4 Scott JT. Mediastinal emphysema and left pneumothorax. Dis Chest 1957;32:421-34

5 Remmelts HHF, Banga JD. Popping pneumothorax. Netherlands J Med 2010;68:187. 